\title{
Contested Chinese dreams of AI? Public discourse about artificial intelligence on WeChat and people's daily online
}

\author{
Zeng, Jing ; Chan, Chung-Hong ; Schäfer, Mike S
}

\begin{abstract}
Artificial intelligence (AI) has become a prominent public issue, particularly in China, where the government has announced plans to turn the country into a global AI power. This study analyses public discourse about AI in China through the conceptual lens of public spheres theory and counter-public spheres. It compares the official AI narrative on People's Daily Online with public discussion about AI on the social medium WeChat, where we assumed that official views would be challenged. Using a combination of qualitative and computational methods, 140,000 AI-related articles published between 2015 and 2018 were studied. Findings reveal that AI-related discourse on WeChat is surprisingly similar to that on People's Daily Online. That is, it is dominated by industry and political actors, such as government agencies and technology companies, and is mostly characterized by discussions about the economic potential of the technology, with strongly positive evaluations, and little critical debate.
\end{abstract}

DOI: https://doi.org/10.1080/1369118X.2020.1776372

Posted at the Zurich Open Repository and Archive, University of Zurich ZORA URL: https://doi.org/10.5167/uzh-190643

Journal Article

Accepted Version

Originally published at:

Zeng, Jing; Chan, Chung-Hong; Schäfer, Mike S (2022). Contested Chinese dreams of AI? Public discourse about artificial intelligence on WeChat and people's daily online. Information, Communication and Society, 25(3):319340.

DOI: https://doi.org/10.1080/1369118X.2020.1776372 


\section{Contested Chinese Dreams of AI? Public Discourse about Artificial Intelligence on WeChat and People's Daily Online}

Jing Zeng ${ }^{\text {**}}$, Chung-hong Chan ${ }^{\mathrm{b}}$, Mike S. Schäfer ${ }^{\mathrm{c}}$

${ }^{a}$ Department of Communication and Media Research, University of Zurich, Zurich, Switzerland; ${ }^{b}$ The Mannheim Centre for European Social Research, University of Mannheim, Mannheim, Germany; ${ }^{c}$ Department of Communication and Media Research, University of Zurich, Zurich, Switzerland

* corresponding author email: j.zeng@ikmz.uzh.ch 


\section{Contested Chinese Dreams of AI? Public Discourse about Artificial Intelligence on WeChat and People's Daily Online}

Artificial intelligence (AI) has become a prominent public issue, particularly in China, where the government has announced plans to turn the country into a global AI power. This study analyses public discourse about AI in China through the conceptual lens of public spheres theory and counter-public spheres. It compares the official AI narrative on People's Daily Online with public discussion about AI on the social medium WeChat, where we assumed that official views would be challenged. Using a combination of qualitative and computational methods, 140,000 AI-related articles published between 2015 and 2018 were studied. Findings reveal that AI-related discourse on WeChat is surprisingly similar to that on People's Daily Online. That is, it is dominated by industry and political actors, such as government agencies and technology companies, and is mostly characterized by discussions about the economic potential of the technology, with strongly positive evaluations, and little critical debate.

Keywords: artificial intelligence, WeChat, science communication, public sphere, counter publics

\section{Introduction}

Since 2015, the Chinese Communist Party, led by President Xi Jinping, has promoted the 'Chinese Dream' (中国梦): the party’s vision of turning China into a strong nation and a cyber-superpower (China Daily, 2015). As a step in realising this vision, the development of artificial intelligence (AI) sectors has been mandated by the ruling party, who have vowed to turn China into a global hub of AI innovation by 2030 (CSC, 2015; Deng, 2018).

Alongside its purported economic benefits (Rao et al., 2017), however, AI carries significant risks and challenges. For instance, it is estimated that over 50 percent of Chinese jobs may become automated in the future - an outcome that could affect over 390 million employees (Manyika et al., 2017: 9). Moreover, the government's potential use of AI for mass surveillance and automated weaponry is another common source of concern among researchers and commentators (Chen, 2018; Larson, 2018; Jacobs, 2018).

In this debate about state-fostered AI development in China, we wondered how the 
Chinese public viewed the government's position. This speculation led to our research question: To what extent do social media serve as a counter-public wherein the official narratives around China's national AI programs are challenged? To address this question, our study interrogated the discursive contestation of AI on two platforms: People's Daily Online (PD) and WeChat.

As the online portal for the People's Daily - China's largest newspaper group (Liang, 2018) - PD broadcasts official messages from the central government. As a mouthpiece of the Central Committee of the Communist Party of China (CPC), its editorials and commentaries represent the official viewpoints of the Chinese authorities (Wu, 2014). WeChat, on the other hand, hosting over one billion active users monthly, is the most popular social media platform in China (Xinhua, 2018). It has over 12 million users on its 'public account platform' (公众账号平台) - a service that allows both individuals and organisations to publish articles ${ }^{1}$ that are visible to all WeChat users (Xinhua, 2017). These public accounts now serve as a primary source of news and other forms of information for Chinese internet users (Yi \& Cheng, 2015; Zhao, 2014).

To analyse AI discourse in China, we collected over 140,000 AI-related articles from WeChat and PD between 2015 and 2018. To examine these articles, we focused on three dimensions that were identified in prior analyses of debates about science-related issues in the public sphere: standing, framing, and positioning (Ferree et al., 2002; Schäfer, 2009; Gerhards \& Schäfer, 2010). These three dimensions were adopted as the theoretical and analytical framework for our study. To operationalise this framework, we used a combination of qualitative analysis and computational methods, including topic modelling and sentiment analysis.

\section{Conceptual Framework}

\subsection{Science and the public sphere}

The public sphere has been conceptualized as a communicative sphere, in which matters of common concern are discussed and opinions formed, and where all proceedings are open to the public (cf. Schäfer, 2015). This concept of the public sphere

\footnotetext{
${ }^{1}$ WeChat articles published by public accounts have various styles. In most cases, they look like news articles or long blog posts.
} 
has been advanced in political and communication theories over several decades (Habermas et al., 1974; Hauser, 1999; Keane, 1995), and has also been introduced to research in science and technology (Gauchat, 2012).

The Sociology of Science, Science and Technology Studies (STS), and other socialscientific analyses of science, have long argued that rhetoric and politics are constitutive of the scientific enterprise (Foucault, 1972; Latour, 1993; Mosco, 2004). Technologies are, according to Mosco (2004: 118), 'mutually constituted out of a culture that creates meaning and a political economy that empowers it.' In this context, the concept of the public sphere serves as a conceptual heuristic to interrogate the intersection between meaning creation and power contestation around science and technology.

Gerhards and Schäfer (2009) introduce the concept of the 'scientific public sphere' to discuss different models of public communication, wherein public opinion of, and societal reactions to science are constructed. They argue that in public spheres, different issues, including science and technology, are publicly discussed, and ultimately evaluated. These public discourses, and their resulting evaluations, influence the implementation of a given technology. In the public sphere, and particularly in mediated platforms such as news media or social media, different stakeholders can position their views on, and evaluations of a technology. In so doing, they endeavour to make their views pervasive, in order to legitimize or undermine the issue in question (Gerhards \& Schäfer, 2009).

While Gerhards and Schäfer analyse Western democracies, their argument is not limited to democratic countries. For a single-party authoritarian country like China, garnering consent for science and technology projects is just as, if not more, necessary. Because the central government plans and finances China's major science and technology projects, the legitimacy of these projects is linked to the legitimacy of the ruling party. Thus, mainstream media, such as $P D$, often function as the party's communication apparatus to influence and guide public opinion (Zhao, 1998; Wu, 2014). In this way, the government exerts its hegemony over a considerable portion of the public sphere.

At the same time, this top-down hegemony can be challenged by dissenting voices from civil society (Yang \& Calhoun, 2007) or grassroots activists (Kay, Zhao, \& Sui, 2015). This bottom-up resistance can constitute counter-public spheres (Negt and Kluge, 1972; 
Fraser, 1990; Downey \& Fenton, 2003) - forms of collective expression that respond to, and potentially challenge mainstream public discourse (Downey \& Fenton, 2003: 194). Counter-public spheres often emerge when this mainstream public discourse fails to provide a rational or critical discourse about an issue of common concern (Calhoun, 1993). As outlined by prior studies on China's public sphere, new information and communication technologies, and social media in particular, have contributed to the emergence of counter-public spheres in that country (Lee, So, \& Leung, 2015; Sima, 2011; Rauchfleisch \& Schäfer, 2015).

\subsection{Analysing Public Debate}

Several scholars have analysed media discourses around AI in recent years, mostly in Western countries. They point out that such discourses are often sensationalised (Goode, 2018), industry-driven (Elish and boyd, 2018), and politicized (Brennen et al., 2018). For instance, Elish and boyd's (2018) study on AI rhetoric reveals that the business community has manufactured an over-hyped vision of AI, by focusing on its potential and exaggerating its methodological capabilities. Similarly, Brennen et al. (2018), in news coverage of AI in the UK, detect a prevalence of industry concerns, such as concerns around products and initiatives. Our study adds to this scholarship.

In focusing on China, this study analysed an under-researched, yet highly relevant case. To understand public and counter-public spheres in China, we used a framework proposed by Ferree et al. (2002) and Gerhard and Schäfer (2009). In their analyses of abortion and biotechnology debate, they developed a conceptual framework to measure public debate around science and technology along three dimensions: standing, framing, and positioning.

- Standing measures the prevalence of different stakeholders in public discourse. In any given debate, the stronger a stakeholder's presence, the more influential s/he is likely to be (Ferree et al., 2002).

- Framing refers to the contextualization and interpretation of a topic. In public discourses around technology and science (and other issues), actors make sense of, and give meaning to an issue by using frames (Gamson \& Modigliani, 1989). These frames entail the way an issue is viewed. For example, is it a political, 
economic, legal, social, or other issue (Entman, 1993); is it seen as a problem; and what measures should be taken by responsible parties in relation to it (Gerhard and Schaefer, 2009: 441)?

- Building on Ferree et al.’s (2002) framework, Gerhards and Schäfer (2009) added positioning as a third dimension. Positioning describes the prevalence of different evaluations of a topic (Gerhard \& Schäfer, 2009). For example, what is a stakeholder's position on an issue, and how is that position presented (i.e. positively or negatively) in the debate in general (Schäfer, 2007)?

We employed all three dimensions to analyse public discourses around AI in China. In our study, $P D$ represents the authoritative realm where the party state's official narratives about AI are propagated. In contrast, WeChat represents a potential counterpublic where multiple actors and narratives can coexist, and contest various issues. To assess to what extent the discussion around AI on WeChat serves as a 'counter-public sphere' that challenges the official discourses presented in $P D$, we compared both platforms. To this end, we asked the following questions: RQ1 - Standing: How diverse is the spectrum of actors participating in AI debates on WeChat?

RQ2 - Framing: How does the framing around AI differ among actors on WeChat, and between WeChat and PD?

RQ3 - Positioning: How does sentiment about AI differ among actors on WeChat, and between WeChat and $P D$ ?

\section{Methods}

\subsection{Data collection}

As WeChat does not have application programming interfaces (APIs), we used a Selenium-based web crawler to retrieve articles published by its public accounts $(\mathrm{Fu}$, 2018). The crawler visited, and sent the search query ' $\square \square \square \square$ ' ('artificial intelligence') to, a third-party search engine - sogou.com - where historical WeChat posts from public accounts are archived. Using the time filter function of Sogou, the crawler collected the 100 articles that were most relevant to the search term from each day of our study period: 1 January 2015 to 1 October 2018. The rationale behind setting 2015 
as the starting point for the data collection was that the Chinese government launched its official AI agenda in that year. We terminated the crawler on 1 October 2018 to begin data analysis. Using another web crawler, we collected news articles from $P D$ 's online search engine - search.people.com.cn - using the same search keyword and timeframe. In total, we collected 128,343 WeChat articles and 20,666 PD articles.

\subsection{Standing}

We employed multi-step coding to identify the actors participating in public discourse surrounding AI on WeChat. We used a weighted sample of WeChat public profiles $(n=1,100)$ from the dataset, and manually annotated them based on information provided in them (i.e. each account's identity verification and function description). In the second step, we organized the labels used for this annotation into categories based on their interrelationship. Seven categories emerged from the data: 1) media organization; 2) tech company; 3) non-tech company; 4) academic; 5) government institution; 6) civil society; and 7) non-institutional account. A detailed codebook with examples is included in Appendix A.

For validation, a second coder coded a random subset of 110 user profiles, using the same codebook. Inter-coder reliability was calculated using Cohen's Kappa, and showed a high degree of agreement between coders $(\kappa=.94)$.

\subsection{Framing}

To investigate the frames used to discuss AI, we employed a two-step procedure. The first step focused on identifying prevalent topics from both WeChat and PD using Latent Dirichlet Allocation (LDA) (Blei et al., 2003). Jieba toolkit (Qin \& $\mathrm{Wu}, 2019)$ was used to generate tokenized versions of articles. We then adopted Maier et al.'s (2018) approach to further pre-process data, and validate different LDA models ${ }^{2}$. Based on the evaluation of topic words, sample articles, and interactive visualizations of LDA, we agreed on topic numbers (k) of 30 and 20 for the most interpretable models

\footnotetext{
${ }^{2}$ This pre-processing step involved removing stop words, sparse terms, and dense terms. We trained LDA models with combinations of $\mathrm{k}(\mathrm{k}=\{10,20, \ldots, 80\})$ and hyper-parameter Alpha $($ alpha $=\{.005, .01, .05, .1, .2, .5,1\})$. Beta was set at 1/k (Maier et al., 2018). For each $\mathrm{k}$, we selected a model with the best topic coherence.
} 
for WeChat and $P D$, respectively. After removing 'boilerplate' topics ${ }^{3}, 26$ topics were eventually identified in the WeChat corpus and 17 in the $P D$ corpus.

In the second step, the identified topics were qualitatively labelled, and grouped into frames by three of the study's authors (Figure 1). For this task, we adopted six frames from the Science Communication literature (Gerhards \& Schäfer, 2010; Schäfer, 2009), as follows:

- The economic frame covers discussion about the economic and financial impacts of AI, on both macroeconomic and microeconomic levels. Topics discussed under this frame included e-commerce, venture capital, and consumer products.

- The scientific frame includes discussion of the scientific aspects of AI development and application. Examples of topics under this frame included research output and science and technology events.

- The entertainment frame covers discussions of AI in the contexts of popular culture, entertainment, sports, and the arts. Movies and DeepMind playing Go were the most common topics within this frame.

- The socio-ethical frame consists of critical reflection on AI's impact on human society and related ethical issues. Topics grouped under this frame included AI risks and threats, and ethics.

- The educational frame addresses the issue of educational institutions' appropriate response to AI. Topics related to this frame included school curriculum and higher education.

- The political frame refers to discussions of AI in the context of government policies, government regulation, and the geopolitical impacts of AI. For example, China's national development plan and regulation were related to this frame.

Using two LDA models, we calculated the thetas $\left(\theta_{\mathrm{f}}\right)^{4}$ of the six frames for each article. The $\theta_{\mathrm{f}}$ can be interpreted as the prominence of a specific frame in an article. For simplicity's sake, we refer to $\theta_{\mathrm{f}}$ as 'theta' in the subsequent sections. Following

\footnotetext{
3 'Boilerplate' topics are those reflecting general language-usage features.

${ }^{4}$ Our LDA models could generate the topic membership probability $\theta_{\mathrm{t}}$ of an article for all topics. These probabilities are mutually exclusive for each article, i.e. $\theta_{\mathrm{t} 1}+\theta_{\mathrm{t} 2}+\ldots+\theta_{\mathrm{tk}}=1$. Suppose we grouped $\mathrm{t} 1, \mathrm{t} 2$ and $\mathrm{t} 9$ into frame $x\left(\mathrm{f}_{\mathrm{x}}\right)$. The frame membership of an article to frame $x\left(\theta_{\mathrm{fx}}\right)$ is equal to the sum of $\theta_{\mathrm{t} 1}, \theta_{\mathrm{t} 2}$ and $\theta_{\mathrm{t} 9}$. According to the sum rule, $\theta_{\mathrm{fx}}$ can be interpreted as the probability of an article falling into $\mathrm{t} 1, \mathrm{t} 2$ or $\mathrm{t} 9$.
} 
Griffiths and Steyvers (2004), we constructed the time series of mean theta for each frame, and for each actor group.

[insert Figure 1 here]

\subsection{Positioning}

In this study, we used sentiment as a proxy for actors' positioning on AI. We conducted a sentiment analysis using the National Taiwan University Semantic Dictionary (NTUSD; Ku et al., 2006). We quantified the sentiment of an article using Relative risk (RR), which is calculated by dividing the number of positive words by the number of negative words plus one, in an article ${ }^{5}$. This metric measures the excess positive sentiment of an article with respect to the negative sentiment.

The accuracy of the dictionary we used can be undermined by its domain-specificity (González-Bailón \& Paltoglou, 2015; Ribeiro et al., 2016), so validation was necessary. Therefore, we validated the dictionary against human-coded sentiment (Haselmayer and Jenny, 2016). The validation results indicate that our sentiment metrics captured the sentiment of AI-related content (Appendix B).

\section{Results}

\subsection{Standing}

In the Chinese public sphere, $P D$ represents the voice of the CPC government (Wu, 2014; Zhao, 1998). In contrast, social media such as WeChat host a wider range of actors. Therefore, the first research question asked how present different actors were in public discourse about AI on WeChat. Through a qualitative study of profiles of WeChat public accounts, we identified seven categories of actors. The numbers of accounts and articles were used to measure the prevalence of each actor category.

The first category - industry actors - consisted of verified WeChat accounts that were affiliated with private companies. This was the most prominent actor category on

\footnotetext{
${ }^{5}$ In Epidemiology, RR is commonly calculated by the division of two risks. To translate this concept into our sentiment analysis, we calculated the RR by dividing the ratio of positive words by the ratio of negative words. Because the bases of the two ratios are the same, the RR value equals the number of positive words divided by the number of negative words. We added one to the number of negative words to solve the problem of division by zero.
} 
WeChat, making up 46.2 percent of all coded accounts. Among these, technology companies such as Microsoft and Tencent were the most prominent, accounting for 28.7 percent of all profiles. Non-tech companies, on the other hand, made up 17.5 percent of this category. These corporate accounts were comparatively active on WeChat, contributing 15,695 articles - more than the sum of articles from all other actors in the sample (Table 1).

Nine point nine percent of accounts were registered by media organizations, including newspaper and television stations. These organizations published an average of 17.3 articles per account; this meant that they were considerably less active than industry actors.

Academic actors referred to verified accounts owned by educational or academic research institutions. While universities and their affiliated research institutions represented a large proportion of the academic actors, their accounts constituted only 4.9 percent of the sample. However, with an average of 39.5 articles per account, they were among the most active actors in the AI debate on WeChat.

Government and civil society actors included government agencies, NGOs, religious groups, and charity organizations. Accounts affiliated with the government and civil society groups constituted 5.2 percent of the sample. The remaining coded WeChat profiles either belonged to accounts that were not affiliated with any verified institution, or no longer existed.

\section{[insert Table 1 here]}

\subsection{Framing}

To compare how AI was framed, we calculated the probability of different platforms and actors using specific frames (as explained in Section 3.2). The results are presented in Figure 2.

\section{[insert Figure 2 here]}

As the government's mouthpiece (Wu, 2014), PD mostly - and unsurprisingly engaged with the economic and political frames. The vast majority of $P D$ articles within these two frames were related to the central government's policies, and promoted narratives around AI's potential to boost China's economic and political power. 
On WeChat, the economic frame was the most commonly used frame across all actor groups. The second most commonly used frame on this platform was the scientific frame, which included discussion of the scientific and technical aspects of AI development. It is worth noting that the scientific frame was discussed not only by academic accounts, but also by government and industry actors. More precisely, while the academic community published articles about AI-related research output and academic events, government and industry actors' discussions within the scientific frame related mainly to the significance of AI research and the technical aspect of AIempowered consumer products.

Civil society groups and government institutions were the most active promoters of the political frame on WeChat, and their framing of AI followed a similar pattern. For example, both civil society groups and government institutions frequently published content similar to PD's news articles - that is, articles that discussed the strategic significance of China becoming an 'AI superpower'. Our analysis also shows that civil society groups were the least engaging actors when it came to discussing the socioethical concerns around AI, such as the impact of AI on human society, and the ethical implications of AI development (i.e. the socio-ethical frame). In comparison, academic and media actors were relatively more active in addressing these critical topics.

To compare frames used on $P D$ and WeChat, we compared each frame's mean theta (Table 2). Our analysis reveals that the economic frame dominated AI discussion on PD and WeChat, with a mean theta higher than .37 in both cases. The most significant disparity between these two platforms lies in their concern for the socio-ethical frame: while it is the third most common frame on WeChat, there is no prevalent topic under this frame on $P D$. The time series plots displayed in Figure 3 and Figure 4 illustrate the temporal evolution of frames; for example, the time series for WeChat's socio-ethical frame illustrates that discussion around AI's socio-ethical implications has sharply decreased on this platform in recent years.

The time series analysis also shows that the economic frame was constantly the most prominent on both platforms, although a slight decrease can be observed on WeChat. Meanwhile, the prominence of the entertainment frame on WeChat and $P D$ fluctuated with media events. For instance, the releases of AI-related movies and DeepMind's participation in Go tournaments sharply boosted the number of articles under the 
entertainment frame.

Meanwhile, the political frame responded to the central government's release of AIrelated policies ${ }^{6}$, as exemplified by China's 2017 Development Plan for AI. In 2017, the Chinese State Council published an official Development Plan to make China the 'innovation centre for AI' (SCS, 2017), and this received extensive coverage on PD. On WeChat, a large number of articles were also published by experts to explain the plan's implications and significance for lay citizens.

[insert Table 2 here] [insert Figure 3 here]

[insert Figure 4 here]

\subsection{Positioning}

To measure the sentiment in each article, we calculated its relative risk (RR), which indicated whether it showed more positive or negative sentiment. For example, articles about China and Chinese researchers' achievements in AI often scored the highest in RR. In contrast, articles discussing AI's threats to human societies generally received the lowest RR. We first broke down our sentiment analysis results from the WeChat data into seven groups of actors, in order to compare each group's RR (Figure 5). The results show that all actor groups discuss AI in a predominantly positive way (all $R R>3.2)$. In particular, government $(R R=5.05)$, civil society $(R R=4.41)$, and academic institutions ( $\mathrm{RR}=4.16)$, have the most positive sentiment scores.

A comparison of the sentiment between WeChat and PD revealed that AI-related content on both platforms showed significantly more positive than negative attitude towards AI ( $R R=3.29 \& 4.47)$. Furthermore, time series analysis of the sentiment metrics (Figure 6) indicates that this positive sentiment continues to increase. The Spearman's rank correlations of RR with time are 0.623 and 0.278 for WeChat and PD respectively, suggesting that the sentiment on both platforms grew more positive over the four years. A particularly high growth rate was observed on WeChat. This is in line

\footnotetext{
${ }^{6}$ Through an analysis of governmental policy documents, we developed a timeline of key AIrelated policies launched in the past four years in China to interpret time series data in context (Appendix C).
} 
with the platform's increasingly prominent discussion about AI's political and technological potency, and its declining focus on its socio-ethical implications. Articles with the lowest RR scores often included the socio-ethical frame, such as discussion around the risks of malfunctioning robots threatening human society. A continuing decrease in the number of articles under this category (as mentioned earlier) helped to boost the overall RR of WeChat.

\section{[Insert Figure 5 here]}

[Insert Figure 6 here]

\section{Discussion}

This study investigated the hypothetical role of WeChat - as a counter-public sphere in China - in challenging the official state media narratives about AI. Focusing on three dimensions of public discussion - standing, framing, and position - this study compared WeChat and PD's four year output (2015 to late 2018) of online articles about AI. This comparison showed that WeChat played a limited role as a counterpublic sphere in challenging $P D$ 's narratives about the economic and political potency of $\mathrm{AI}$.

The economic interest in the country's AI development is extensive, and highly relevant to various sectors. According to one estimate (Rao et al., 2017), AI could provide a 26 percent boost to China's GDP by 2030, thus making it the world's largest economic beneficiary of AI. This economic motivation behind China's ambitions for AI is well reflected in PD's excessive focus on the economic frame. When interwoven political and economic interests combine to materialise China's (so-called) 'AI dream', the resulting positioning of the technology in the media is predictably rosy. As demonstrated by our sentiment analysis, the state media adopts an exceedingly favourable attitude to AI, and this positivity is increasing.

Against the background of this one-sided and overconfident interpretation of AI in the official discourse, a counter-public sphere should present a standing that goes beyond interest groups; promote frames other than the purely economic; and take a position that examines the ethical and social implications of technology more critically.

With regard to standing, our analysis of user profiles on WeChat reveals a diversity of social actors. These actors included industry institutions, government, academia, the 
media, and civil society. However, this actor diversity did not necessarily result in an equal distribution of influence: industry actors were still the most prevalent and visible actors on WeChat, and they contributed most of the AI-related content.

In the case of framing, our findings show that all actor groups were united in their promotion of the economic frame on WeChat. One surprisingly active participant in promoting this frame was academia. It is worth pointing out that academic actors' close engagement in discussion of the economic impacts of AI should be interpreted within the context of a growing collaboration between academic institutions and industries. As in other countries, Chinese AI researchers are often involved in both academic and industry sectors (Larson, 2018).

Results from this study reveal that civil society groups served as an amplifier of political and economic frames. This seemingly surprising finding needs to be put into perspective by looking at the relationship between civil society organisations and political institutions in China. As Chinese civil society groups rely on the government for their existence, they need to maintain a close and harmonious relationship with the authorities and, thus, do not challenge them (Dai, Zeng, \& Wang, 2017; Hsu \& Hasmath, 2014). This explains why civil society groups' framing of AI focused on the economic aspect of its development, thus adopting an almost identical approach to that of the government.

Findings related to the socio-ethical frame offer key insights into the assessment of WeChat's role as a counter-public sphere. As Wagner et al. (2002: 341) point out, the public is motivated to develop an understanding of new technology. This motivation is not fuelled by its unfamiliarity, however, but by controversies that surround it. Likewise, Goode (2018) also argues that controversy is crucial in stimulating the public's critical reflection on emerging technologies. In the context of the current study, such controversy can be epitomized in the socio-ethical frame. Our analysis shows that WeChat did bring public attention to this crucial subject, despite its absence on $P D$. At the same time, the time series analysis indicates that the prevalence of the socio-ethical frame has been declining sharply over the past five years. This trend implies that AI discussions on WeChat are becoming increasingly homogeneous, as critical voices weaken. 
In the case of positioning, our analysis reveals the same growing positive sentiment toward AI on WeChat as there is on PD. On the one hand, this finding reflects the general openness to, and enthusiasm for digital technology in the wider Chinese society (Lv, 2005; Kostka, 2018). On the other hand, it underscores the need for experts to shake the public out of their complacency.

As previously mentioned, an over-hyped and economy-focused coverage of AI is not unique to Chinese media, but has also been documented in prior studies of Western media (Brennen et al., 2018; Elish and boyd, 2018). What is different in China is the continuing absence of vocal and influential communities that reveal the 'blind spots' within the current AI discourse. In Europe and the US, an expanding league of activists and scholars have been actively advocating for, and raising awareness of, ethical, accountable, and sustainable AI development ${ }^{7}$. In China, the responsibility to foster a similar movement is now on the shoulders of researchers, especially those with social science and humanities backgrounds.

\section{Conclusion}

In Cath et al.'s (2018) vision of a 'good AI society' for the US, EU, and the UK, AI's power should be fully steered towards promoting the public good. In the case of China, what constitutes the public good, and the way it can be delivered, relies on a rational and inclusive counter-public sphere. In such a sphere, grassroots discourse challenges official doctrines. Existing literature often depicts new communication technologies in China as a counter-public sphere that competes against the heavily regulated mainstream media (Lee, So, \& Leung, 2015; Sima, 2011; Rauchfleisch \& Schäfer, 2015). However, our study suggests that social media's role as a counter-public sphere in AI discourses is minimal.

The lack of a counter-public sphere to influence China's vision and strategies related to AI can be detrimental. When an entire nation - from academia to the business sphere and from the government to civil society - is collectively and uncritically working on AI's rapid expansion, the consequences can be severe. As demonstrated by the recent CRISPR babies scandal in China (Kuo, 2018), when ambition overrules regulation and

${ }^{7}$ Some sample institutions include The Institute for Ethical AI \& Machine Learning (UK); The AI Now Institute (US); and The Future of Life Institute (US). 
when self-interest overrules ethical consideration, technological 'innovation' can have profound consequences. Similarly, in the case of China's AI development, if the current trajectory continues to be driven solely by political and economic interests, the results can have irreversibly devastating consequences.

The future trajectory of China's AI dream remains hard to predict. Our analysis shows that the official rhetoric about AI is highly responsive to external events. A single policy change from the central government can drastically alter the AI sector. The powerful influence of the Chinese government can be a double-edged sword. On the one hand, the official AI discourse exercises a hegemonic power over public opinion on the issue, thus limiting healthy debate and critical reflection. On the other, this centralised power grants Chinese authorities a certain responsive advantage over its Western counterparts when it comes to quickly and effectively implementing policies. For example, if the government saw an advantage in approaching AI development with more caution and critical reflection, it could, in theory, quickly alter its trajectory and implement policies to reflect this new approach.

The shift mentioned above is not impossible. In Europe and the US, transparency and accountability are held as two fundamental values to guide policymakers' AI schemes (Cath et al., 2018). If China wants to become a real 'AI superpower' and compete against these two powers, it has to catch up in, even lead, the development of a substantive ethical framework. As this paper is being written, the US-China trade war is still unfolding. One important lesson for China to learn from the US sanctions on its technology products is that both China and its technology sector have to work to rebuild the West's trust. Setting a high ethical standard with regards to transparency and accountability might be an effective starting point.

There are limitations to this study. First, Chinese social media are heavily regulated, and criticism of the central government is heavily censored. Some AI-related articles on WeChat, for example, might have been censored. To investigate this possibility, we used an archive of censored WeChat posts - FreeWeChat (McDevitt, 2016) - to search for deleted posts on the AI topic. This search (in December 2019) returned only four articles that contained the term 'artificial intelligence' ( $\square \square \square \square$ ), and none of these discussed AI as its main topic. Furthermore, earlier research of online censorship in China suggests that discussion of non-politically sensitive topics is less prone to 
censorship (Fu, Chan, \& Chau, 2013; King, Pan, and Roberts, 2014; Zeng, Chan, Fu, 2018). While we cannot entirely eliminate the possibility that articles might have been censored, both our investigation of archived deleted social media posts and previous studies, suggest that censorship has a limited impact.

Second, we chose a dictionary-based approach to develop a preliminary sentiment profile of the 140,000 articles collected and analysed in this study. Even though we employed manual coding for validation, dictionary-based approaches to assessing sentiment still have certain shortcomings, such as the over-simplification of human perception of emotion in a text (González-Bailón \& Paltoglou, 2015; Ribeiro et al., 2016; Puschmann, 2018). Future studies should consider conducting sentiment analysis on this large data set with machine learning tools, which use human-coding to train sentiment assessment algorithms (González-Bailón \& Paltoglou, 2015). 


\section{References}

Blei, D., Ng, A., \& Jordan, M. (2003). Latent Dirichlet. Learning Research, 3:9931022.

Boukes, M., van de Velde, B., Araujo, T., \& Vliegenthart, R. (2019). What's the Tone? Easy Doesn’t Do It: Analyzing Performance and Agreement Between Off-theShelf Sentiment Analysis Tools. Communication Methods and Measures, 1-22.

Brennen, J. S., Howard, P. N., and Nielsen, R. K. (2018). An Industry-Led Debate: How UK Media Cover Artificial Intelligence. Available at https://reutersinstitute.politics.ox.ac.uk/sites/default/files/201812/Brennen_UK_Media_Coverage_of_AI_FINAL.pdf

Calhoun, C. (1993) 'Civil Society and the Public Sphere', Public Culture 5(2): 267-80.

Cath, C., Wachter, S., Mittelstadt, B., Taddeo, M., \& Floridi, L. (2018). Artificial Intelligence and the 'Good Society': the US, EU, and UK approach. Science and Engineering Ethics, 24(2), 505-528.

Chan, A. (2007). Guiding public opinion through social agenda-setting: China's media policy since the 1990s. Journal of Contemporary China, 16(53), 547-559.

Chen, S (2018, November 8) China's brightest children are being recruited to develop AI 'killer bots'. In South China Morning Post. Available at https://www.scmp.com/news/china/science/article/2172141/chinas-brightest-children-arebeing-recruited-develop-ai-killer

Chinese State Council (2015) $\square$ 务 $\square \square \square$ 积极 $\square$ 进' $\square$ 联网+’ $\square$ 动 $\square \square$ 导 $\square$ 见. Available at: www.gov.cn/zhengce/content/2015-07/04/content_10002.htm

Dai, J., Zeng, F., \& Wang, Y. (2017). Publicity strategies and media logic: communication campaigns of environmental NGOs in China. Chinese Journal of Communication, 10(1), 38-53.

Deng, I. (2018 July 17) China's AI industry gets the most funding, but lags the US in key talent, says Tsinghua. In South China Morning Post. Available at: https://www.scmp.com/tech/china-tech/article/2155600/chinas-ai-industry-getsmost-funding-lags-us-key-talent-says

Ding, J. (2018). Deciphering China's AI Dream. Future of Humanity Institute, University of Oxford. Available at https://www.fhi.ox.ac.uk/wpcontent/uploads/Deciphering_Chinas_AI-Dream.pdf

Downey, J., \& Fenton, N. (2003). New media, counter publicity and the public sphere. New media \& society, 5(2), 185-202. 
Elish, M. C., \& Boyd, D. (2018). Situating methods in the magic of Big Data and AI. Communication Monographs, 85(1), 57-80.

Entman, R. M. (1993). Framing: Toward clarification of a fractured paradigm. Journal of communication, 43(4), 51-58.

Ferree, M. M., Gamson, W. A., Rucht, D., \& Gerhards, J. (2002). Shaping abortion discourse: Democracy and the public sphere in Germany and the United States. Cambridge University Press.

Foucault, M. (1972). The Archaeology of Knowledge. New York: Pantheon.

Fraser, N. (1990). Rethinking the public sphere: A contribution to the critique of actually existing democracy. Social text, 25/25(1990), 56-80.

Fu, K. W., Chan, C. H., \& Chau, M. (2013). Assessing censorship on microblogs in China: Discriminatory keyword analysis and the real-name registration policy. IEEE Internet Computing, 17(3), 42-50.

Fu K. W. (2018). Mobile App Crawling for Internet Research: WeChat Official Account as a Case Study. Paper presented at the 68th International Communication Association, Prague, Czech Republic. 2018

Gauchat, G. (2012). Politicization of science in the public sphere: A study of public trust in the United States, 1974 to 2010. American sociological review, 77(2), 167-187.

Gerhards, J., \& Schäfer, M. S. (2009). Two normative models of science in the public sphere: human genome sequencing in German and US mass media. Public Understanding of Science, 18(4), 437-451.

González-Bailón, S., \& Paltoglou, G. (2015). Signals of Public Opinion in Online Communication: A Comparison of Methods and Data Sources. The ANNALS of the American Academy of Political and Social Science, 659(1), 95-107. https://doi.org/10.1177/0002716215569192

Goode, L. (2018). Life, but not as we know it: AI and the popular imagination. Culture Unbound: Journal of Current Cultural Research, 10(2), 185-207.

Griffiths, T. L., \& Steyvers, M. (2004). Finding scientific topics. Proceedings of the National academy of Sciences, 101(suppl 1), 5228-5235.

Habermas, J., Lennox, S., \& Lennox, F. (1974). The public sphere: An encyclopedia article (1964). New German Critique, (3), 49-55. 
Haselmayer, M., \& Jenny, M. (2017). Sentiment analysis of political communication: combining a dictionary approach with crowdcoding. Quality \& quantity, 51(6), 2623-2646.

Hauser, G. A. (1999). Vernacular voices: The rhetoric of publics and public spheres. University of South Carolina Press.

He, Y. (2018). AI \& Global Governance: Developing Resilient Economies in the Age of AI. Available at https://cpr.unu.edu/ai-global-governance-developing-resilienteconomies-in-the-age-of-ai.html

Hsu, J. Y., \& Hasmath, R. (2014). The local corporatist state and NGO relations in China. Journal of contemporary China, 23(87), 516-534.

Jacobs, H. (2018, July 15) China's 'Big Brother' surveillance technology isn't nearly as all-seeing as the government wants you to think. In South China Morning Post. Available at https://www.businessinsider.com/china-facial-recognition-limitations-2018$7 ? \mathrm{r}=\mathrm{US} \& \mathrm{IR}=\mathrm{T}$

Kay, S., Zhao, B., \& Sui, D. (2015). Can social media clear the air? A case study of the air pollution problem in Chinese cities. The Professional Geographer, 67(3), 351363.

Keane, J. (1995). 'Structural Transformations of the Public Sphere.' The Communication Review 1: 1-22. doi:10.1080/10714429509388247.

King, G., Pan, J., \& Roberts, M. E. (2014). Reverse-engineering censorship in China: Randomized experimentation and participant observation. Science, 345(6199), 1251722 .

Kostka, G. (2018). China's social credit systems and public opinion: explaining high levels of approval. Available at SSRN: https://ssrn.com/abstract=3215138 or http://dx.doi.org/10.2139/ssrn.3215138.

Ku, LW, Liang YT, \& Chen HH (2006). Opinion extraction, summarization and tracking in news and blog corpora. in Proceedings of AAAI-CAAW'06.

Ku KW \& Chen HH (2007). Mining Opinions from the Web: Beyond Relevance Retrieval. Journal of American Society for Information Science and Technology, Special Issue on Mining Web Resources for Enhancing Information Retrieval, 58(12), pages 1838-1850.

Kuo, L. (2018, November 29) Work on gene-edited babies blatant violation of the law, says China. The Guardian. Available at 
https://www.theguardian.com/science/2018/nov/29/work-on-gene-edited-babiesblatant-violation-of-the-law-says-china

Larson, C. (2018) China's AI imperative. In Science 359 (6476): 628-630.

Lee, P. S., So, C. Y., \& Leung, L. (2015). Social media and Umbrella Movement: Insurgent public sphere in formation. Chinese Journal of Communication, 8(4), 356-375.

Liang, J. (2016). Introduction to People's Daily Online. People's Daily Online.

Available at: en.people.cn/n3/2018/0706/c90828-9478507.html

Luo, Y. (2014). The Internet and agenda setting in China: The influence of online public opinion on media coverage and government policy. International Journal of Communication, 8, 24.

Lv, M., Li, A., Liu, T., \& Zhu, T. (2015). Creating a Chinese suicide dictionary for identifying suicide risk on social media. PeerJ, 3, e1455.

Lv, Y. H. (2005). Privacy and data privacy issues in contemporary China. Ethics and Information Technology, 7(1), 7-15.

McDevitt, D. (2016, November 21). FREEWechat now live. Available at: https://www.opentech.fund/news/freewechat-now-live/

Maier, D., Waldherr, A., Miltner, P., Wiedemann, G., Niekler, A., Keinert, A., \& Schmid-Petri, H. (2018). Applying LDA topic modeling in communication research: Toward a valid and reliable methodology. Communication Methods and Measures, 12(2-3), 93-118.

Manyika, J., Bughin, J., Chui, M., Miremadi, M., George, K., Willmott, P., Dewhurst, M. (2017). A future that works: Automation, employment, and productivity. McKinsey. Available at https://www.mckinsey.com/featured-insights/digitaldisruption/harnessing-automation-for-a-future-that-works

Mimno, D., \& Blei, D. M. (2011). Bayesian checking for topic models. Proceedings of the 2011 Conference on Empirical Methods in Natural Language Processing, $227-237$.

Mistreanu, S. (2018, April 3). Life inside China's Social credit laboratory. Foreign Policy. Available at https://foreignpolicy.com/2018/04/03/life-inside-chinassocial-credit-laboratory/

Mohammad, S. M., \& Turney, P. D. (2010, June). Emotions evoked by common words and phrases: Using mechanical turk to create an emotion lexicon. In Proceedings of the NAACL HLT 2010 workshop on computational approaches to analysis and 
generation of emotion in text (pp. 26-34). Association for Computational Linguistics.

Negt, O. and A. Kluge (1972) Public Sphere and Experience: Towards an Analysis of the Bourgeois and Proletarian Public Sphere. Minneapolis, MN: University of Minnesota Press.

Puschmann, C., \& Powell, A. (2018). Turning Words Into Consumer Preferences: How Sentiment Analysis Is Framed in Research and the News Media. Social Media + Society, 4(3): 1-12.

Qin, W., \& Wu, Y. (2018) jiebaR: Chinese Text Segmentation. R Package version 0.9.99. Available at https://cran.r-project.org/web/packages/jiebaR/index.html

Rao, D. A. S.,Verweij, G., \& Cameron, E. (2017). Sizing the prize: What's the real value of AI for your business and how can you capitalise?. Pwc. Availabe at https://www.pwc.com/gx/en/issues/data-and-analytics/publications/artificialintelligence-study.html

Rauchfleisch, A., \& Schäfer, M. S. (2015). Multiple public spheres of Weibo: A typology of forms and potentials of online public spheres in China. Information, Communication \& Society, 18(2), 139-155.

Ribeiro, F. N., Araújo, M., Gonçalves, P., Gonçalves, M. A., \& Benevenuto, F. (2016). Sentibench-a benchmark comparison of state-of-the-practice sentiment analysis methods. EPJ Data Science, 5(1), 1-29.

Schäfer, M. S. (2009). From public understanding to public engagement: An empirical assessment of changes in science coverage. Science Communication, 30(4), 475505.

Schäfer, Mike S. (2015). Digital Public Sphere. In Mazzoleni, Gianpietro (Ed.) The International Encyclopedia of Political Communication. London: Wiley Blackwell. 322-328.

Sima, Y. (2011). Grassroots environmental activism and the Internet: Constructing a green public sphere in China. Asian Studies Review, 35(4), 477-497.

Soroka, S. N. (2002). Agenda-setting dynamics in Canada. Vancouver: UBC Press.

State Council of China (2017). Notice of The Next-Generation Artificial Intelligence Development Plan. Available at: http://www.gov.cn/zhengce/content/201707/20/content_5211996.htm 
Wagner, W., Kronberger, N., \& Seifert, F. (2002). Collective symbolic coping with new technology: Knowledge, images and public discourse. British Journal of Social Psychology, 41(3), 323-343.

Wu, S. (2014). The Revival of Confucianism and the CCP's Struggle for Cultural Leadership: a content analysis of the People's Daily, 2000-2009. Journal of Contemporary China, 23(89), 971-991.

Xinhua. (2017). $\square \square \square \square \square \square \square$ 仅 10\% $\square$ 续关 $\square$ 专 $\square \square$ 进 $\square \square \square \square$. Available at www.xinhuanet.com/2017-02/06/c_1120420229.htm

Xinhua (2018, March 05). 马 $\square$ 腾 $\square \square \square \square \square \square \square$ 跃 $\square$ 户数 $\square \square \square \square \square$ 亿. In Xinhua. Available at www.xinhuanet.com/2018-03/05/c_1122488991.htm

Yang, G., \& Calhoun, C. (2007). Media, civil society, and the rise of a green public sphere in China. China Information, 21(2), 211-236.

Yi, Q. \& Cheng, T. (2015). $\square \square \square \square \square \square \square \square$ 闻传 $\square \square \square \square \square$. 传 $\square \square \square$ 权. 2015 (6): 78-82.

Yuan, B., Liu, Y., \& Li, H. (2013). Sentiment classification in Chinese microblogs: lexicon-based and learning-based approaches. International Proceedings of Economics Development and Research, 68, 1.

Zeng, J., Chan, C. H., \& Fu, K. W. (2017). How Social Media Construct ‘Truth’ Around Crisis Events: Weibo's Rumor Management Strategies After the 2015 Tianjin Blasts. Policy \& internet, 9(3), 297-320.

Zhao, Y. (1998). Media, market, and democracy in China: Between the party line and the bottom-line (Vol. 139). University of Illinois Press.

Zhao, Y. (2014). $\square \square \square \square \square \square \square$ 纸 $\square \square \square \square \square \square \square \square \longrightarrow \square \square$ 扬 $\square \square$ 报 $\square \square \square \square \square \square \square \square$ 为. $\square$ 传 $\square$ 2014 (10): 36-38 


\section{Appendix A: codebook for actors}

[insert Table 3 here]

\section{Appendix B: Validation of NTUSD}

We randomly selected 500 articles from our WeChat and PD corpora. We restricted our inclusion criteria to articles less than 1500 words in order to reduce the cognitive loading of the crowd-coding task (Mohammad \& Turney, 2010).

We used the crowdsourcing platform - Figure Eight (figure-eight.com) - for this task. Participants understand Simplified Chinese and English. They were asked to code each article's sentiment using a 4-point ordinal scale. Figure 7 shows a screenshot of the crowd-coding screen.

$$
\text { [insert Figure } 7 \text { here] }
$$

For each article, three coding results from different participants were collected. We calculated the human-coded sentiment scores by averaging the result from three coders. Figure 8 shows the scatterplot of human-coded scores and relative risk metrics derived from NTUSD. A regression line is also displayed.

The correlation between the two variables is statistically significant (Pearson's correlation: $0.238, \mathrm{p}<0.0001)$. Because 'off-the-shelf' sentiment dictionaries are commonly used without revalidation, there is no established threshold of correlation for accepting a dictionary. However, by comparing our result with a handful of priors attempts to revalidate off-the-shelf dictionaries (Haselmayer \& Jenny, 2016; Boukes et al., 2019), we can argue that our validation result is acceptable. As the correlation is statistically significant, we deem the criterion validity of our measurement to be adequate.

[insert Figure 8 here]

\section{Appendix C Timeline of Chinese government's AI policies}

[insert Table 4] 


\section{Tables}

Table 1 . Summary of actor categories.

\begin{tabular}{|c|c|c|c|c|}
\hline \multicolumn{2}{|c|}{ Actor categories } & \multirow{2}{*}{$\begin{array}{l}\text { Accounts (in \%) } \\
\begin{array}{c}28.7 \\
\mathrm{n}=316\end{array}\end{array}$} & \multirow{2}{*}{$\begin{array}{l}\begin{array}{l}\text { Number of } \\
\text { articles }\end{array} \\
12,984\end{array}$} & \multirow{2}{*}{$\begin{array}{l}\begin{array}{l}\text { Average number of } \\
\text { articles per account }\end{array} \\
41.1\end{array}$} \\
\hline Industry & $\begin{array}{l}\text { technology } \\
\text { companies }\end{array}$ & & & \\
\hline & $\begin{array}{l}\text { non-tech } \\
\text { companies }\end{array}$ & $\begin{array}{r}17.5 \\
n=192\end{array}$ & 2,711 & 14.1 \\
\hline \multicolumn{2}{|c|}{ Media organizations } & $\begin{array}{r}9.9 \\
n=109\end{array}$ & 1,881 & 17.3 \\
\hline \multicolumn{2}{|c|}{ Academic } & $\begin{array}{r}4.9 \\
n=54\end{array}$ & 2,133 & 39.5 \\
\hline \multicolumn{2}{|c|}{ governmental institutions } & $\begin{array}{r}3.6 \\
n=40\end{array}$ & 411 & 10.3 \\
\hline \multicolumn{2}{|c|}{ Civil Society } & $\begin{array}{r}1.6 \\
n=18\end{array}$ & 251 & 13.9 \\
\hline \multicolumn{2}{|c|}{ non-institutional accounts } & $\begin{array}{r}30.7 \\
n=338\end{array}$ & 4,433 & 13.1 \\
\hline \multicolumn{2}{|l|}{ Other } & $\begin{array}{r}3.0 \\
n=33\end{array}$ & 526 & 15.9 \\
\hline
\end{tabular}

Table 2. Framing in AI articles - Mean theta (95\% Confidence Interval)]

\begin{tabular}{|c|c|c|}
\hline & $\begin{array}{r}\text { WeChat } \\
(n=124,711)\end{array}$ & $\begin{array}{r}P D \\
(n=20,666)\end{array}$ \\
\hline Economic frame & 0.376 (0.375 to 0.378$)$ & 0.398 (0.0296 to 0.402$)$ \\
\hline Scientific frame & 0.165 (0.164 to 0.166$)$ & 0.116 (0.114 to 0.119$)$ \\
\hline Socio-ethical frame & $0.0878(0.0871$ to 0.0886$)$ & \\
\hline Entertainment frame & $0.0823(0.0816$ to 0.0830$)$ & $\begin{array}{r}0.0866(0.0845 \text { to } \\
0.0888)\end{array}$ \\
\hline Political frame & $0.0804(0.0797$ to 0.0810$)$ & $0.135(0.132$ to 0.137$)$ \\
\hline Educational frame & 0.0740 (0.0734 to 0.0745$)$ & $\begin{array}{r}0.0308(0.0296 \text { to } \\
0.0321)\end{array}$ \\
\hline
\end{tabular}


Table 3. Codebook for actors

\begin{tabular}{|c|c|c|c|}
\hline \multicolumn{2}{|c|}{ Category } & Description & Example \\
\hline \multicolumn{2}{|c|}{$\begin{array}{l}\text { Media } \\
\text { organisation }\end{array}$} & $\begin{array}{l}\text { The account explicitly indicates that the account is associated with a media } \\
\text { organisation, including newspapers, magazines, television, and new media } \\
\text { companies. Individuals authenticated with these media organisations were also } \\
\text { coded under this category. }\end{array}$ & $\begin{array}{l}\text { - } \quad \text { Qinhuangdao Daily } \\
\text { - } \quad \text { Beijing Youth Weekly }\end{array}$ \\
\hline \multirow{2}{*}{$\begin{array}{l}\stackrel{\gtrless}{ \pm} \\
\stackrel{0}{D} \\
\stackrel{0}{=}\end{array}$} & $\begin{array}{l}\text { technology / } \\
\text { IT company }\end{array}$ & $\begin{array}{l}\text { The account explicitly indicates that it is associated with a technology or an IT } \\
\text { company. Individuals authenticated with these companies were also coded under this } \\
\text { category. }\end{array}$ & $\begin{array}{ll}- & \text { TenCent } \\
\text { - } & \text { Microsoft_Al_Toutiao }\end{array}$ \\
\hline & $\begin{array}{l}\text { non-tech } \\
\text { companies }\end{array}$ & $\begin{array}{l}\text { The account explicitly indicates that it is associated with non-tech and non-media } \\
\text { institutions. Individuals authenticated with these companies were also coded under } \\
\text { this category. }\end{array}$ & $\begin{array}{ll}\text { - } & \text { Red Star Macalline } \\
\text { - } & \text { Guotai Junan Securities }\end{array}$ \\
\hline \multicolumn{2}{|c|}{ Academic } & $\begin{array}{l}\text { The account explicitly indicates that it is associated with an academic or educational } \\
\text { institution Individuals authenticated with these institutions were also coded under this } \\
\text { category. }\end{array}$ & $\begin{array}{ll}- & \text { Tsinghua University } \\
\text { - } & \text { Chinese Academic of Science }\end{array}$ \\
\hline \multicolumn{2}{|c|}{$\begin{array}{l}\text { Governmental } \\
\text { institutions }\end{array}$} & $\begin{array}{l}\text { The account explicitly indicates that the account is associated with a central or } \\
\text { regional governmental body. Individuals authenticated with these institutions were } \\
\text { also coded under this category. }\end{array}$ & $\begin{array}{l}\text { - Jiang Yin Municipal Commission of } \\
\text { Economy and Informatization, } \\
\text { - SME Bureau of Chongqing }\end{array}$ \\
\hline \multicolumn{2}{|c|}{ Civil Society } & $\begin{array}{l}\text { The account explicitly indicates that the account is associated with civil society } \\
\text { organisations, including NGOs, charitable organizations, religion-based } \\
\text { organizations, and professional associations. Individuals authenticated with these } \\
\text { organizations were also coded under this category. }\end{array}$ & $\begin{array}{l}\text { - Human Resource Non-Governmental } \\
\text { Organization, } \\
\text { - Shanghai Jiading Fanxiejiao } \\
\text { Association }\end{array}$ \\
\hline \multicolumn{2}{|c|}{ Non-institutional } & Accounts without authentication as an institution. & - Renwu story \\
\hline \multicolumn{2}{|c|}{ Other } & $\begin{array}{l}\text { Accounts' associated with users other than the categories listed above, or accounts } \\
\text { that no longer exist. }\end{array}$ & $\begin{array}{ll}\text { - } & \text { FilmHorn, } \\
\text { - } & \text { Leifeng Wang }\end{array}$ \\
\hline
\end{tabular}


Table 4. Timeline of Chinese government's AI policies

\begin{tabular}{|c|c|c|}
\hline $\begin{array}{l}\text { Publish } \\
\text { Time }\end{array}$ & Issuing Body & Policy Title \\
\hline 2015 May & State Council & Made in China 2015 \\
\hline 2015 July & State Council & $\begin{array}{l}\text { Guiding Opinions of the State Council on Vigorously } \\
\text { Advancing the "Internet Plus" Action }\end{array}$ \\
\hline 2016 March & $\begin{array}{l}\text { National } \\
\text { Congress }\end{array}$ & $\begin{array}{l}\text { Outline of the 13th Five-Year Plan for the National } \\
\text { Economic and Social Development of the PRC }\end{array}$ \\
\hline 2016 April & $\mathrm{MI}, \mathrm{NDRC}, \mathrm{MF}$ & Robot industrial developing plan(2016-2020) \\
\hline 2016 May & $\begin{array}{l}\text { NDRC, MST, } \\
\text { MIIT, CCAC }\end{array}$ & $\begin{array}{l}\text { 'Internet Plus' Artificial Intelligence Three-Year Action } \\
\text { Implementation Plan }\end{array}$ \\
\hline 2016 July & MST & $\begin{array}{l}\text { Circular of the State Council on Issuing the National } \\
\text { Scientific and Technological Innovation Planning for the } \\
\text { 13th Five Years }\end{array}$ \\
\hline 2016 September & MIIT, NDRC & $\begin{array}{l}\text { Innovation and development of intelligent hardware } \\
\text { industry initiative (2016-2018) }\end{array}$ \\
\hline 2016 November & State Council & $\begin{array}{l}\text { the 13th Five-Year National Plan for the Development of } \\
\text { Strategic Emerging Industries }\end{array}$ \\
\hline 2017 March & 12th NPCPRC & Report on the Work of the Government 2017 \\
\hline 2017 July & State Council & $\begin{array}{l}\text { Notice of the State Council on Issuing the Development } \\
\text { Plan on the New Generation of Artificial Intelligence }\end{array}$ \\
\hline 2017 October & CPC & 19th CPC National Congress \\
\hline 2017 December & MIIT, MST & $\begin{array}{l}\text { Three-Year Action Plan for Promoting Development of a } \\
\text { New Generation Artificial Intelligence Industry (2018- } \\
\text { 2020) }\end{array}$ \\
\hline 2018 March & 13th NPCPRC & Report on the Work of the Government 2018 \\
\hline
\end{tabular}

Notes: PRC: the People's Republic of China

MI: Ministry of Industry

NDRC: National Development and Reform Commission

MF: Ministry of Finance

MST: Ministry of Science and Technology

MIIT: Ministry of Industry and Information Technology

CCAC: Office of the Central cyberspace affairs commission

NPCPRC: National People's Congress of the People's Republic of China 


\section{Figures}
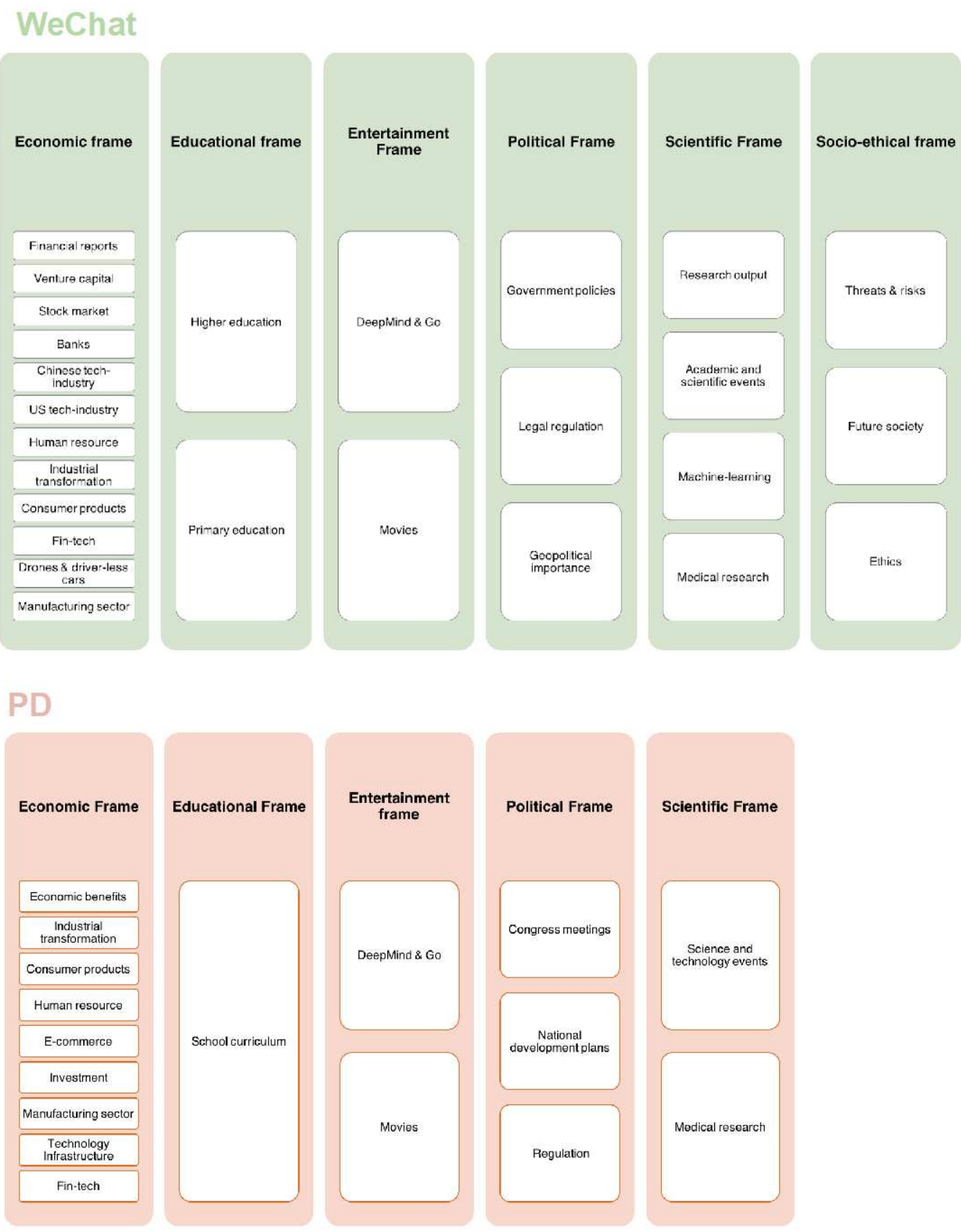

Figure 1. Topic arrangement of WeChat and $P D$ articles. 


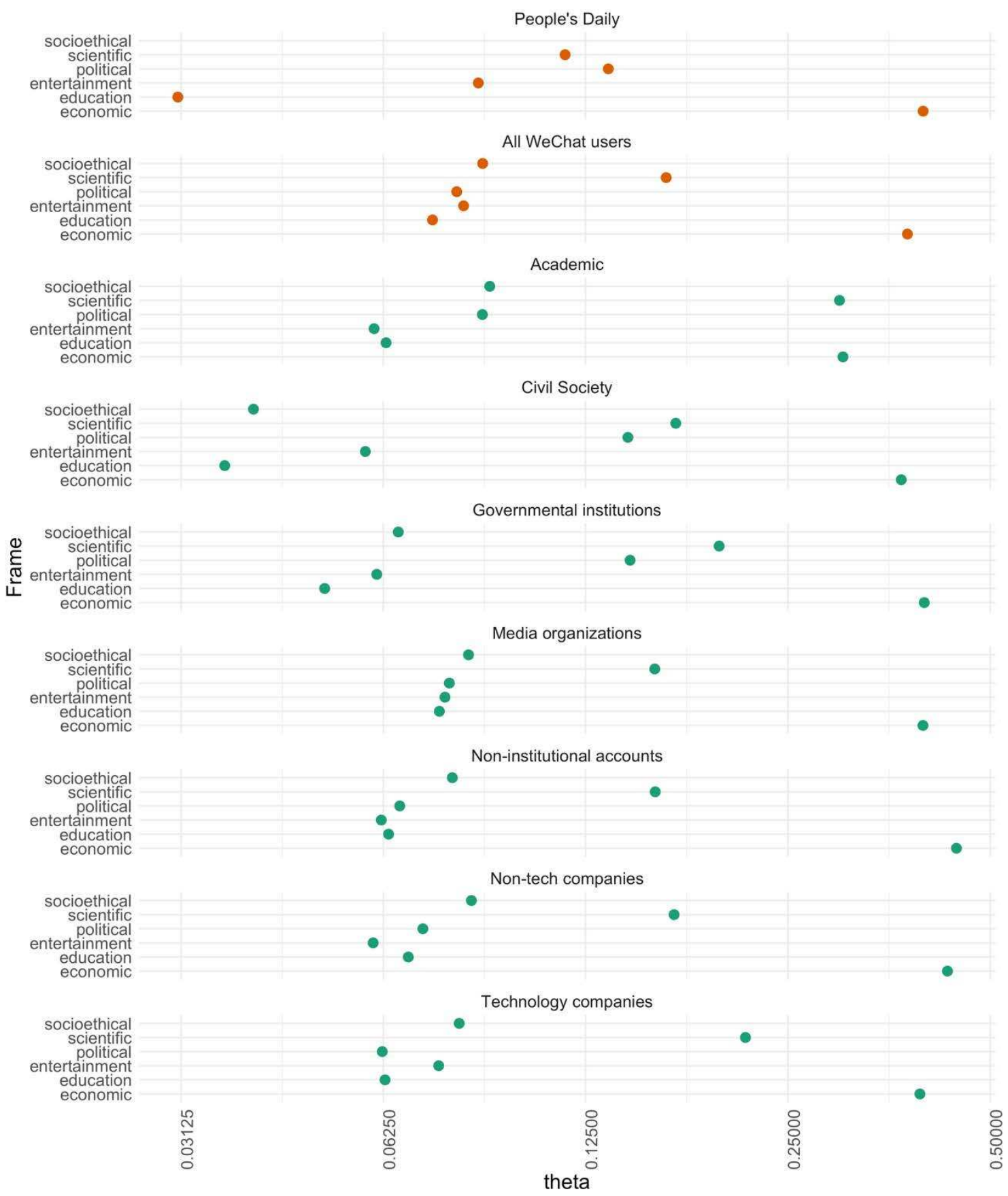

Figure 2. Average theta for each frame of AI articles published by each actor group.

(Note: $\mathrm{x}$-axes are log-transformed) 


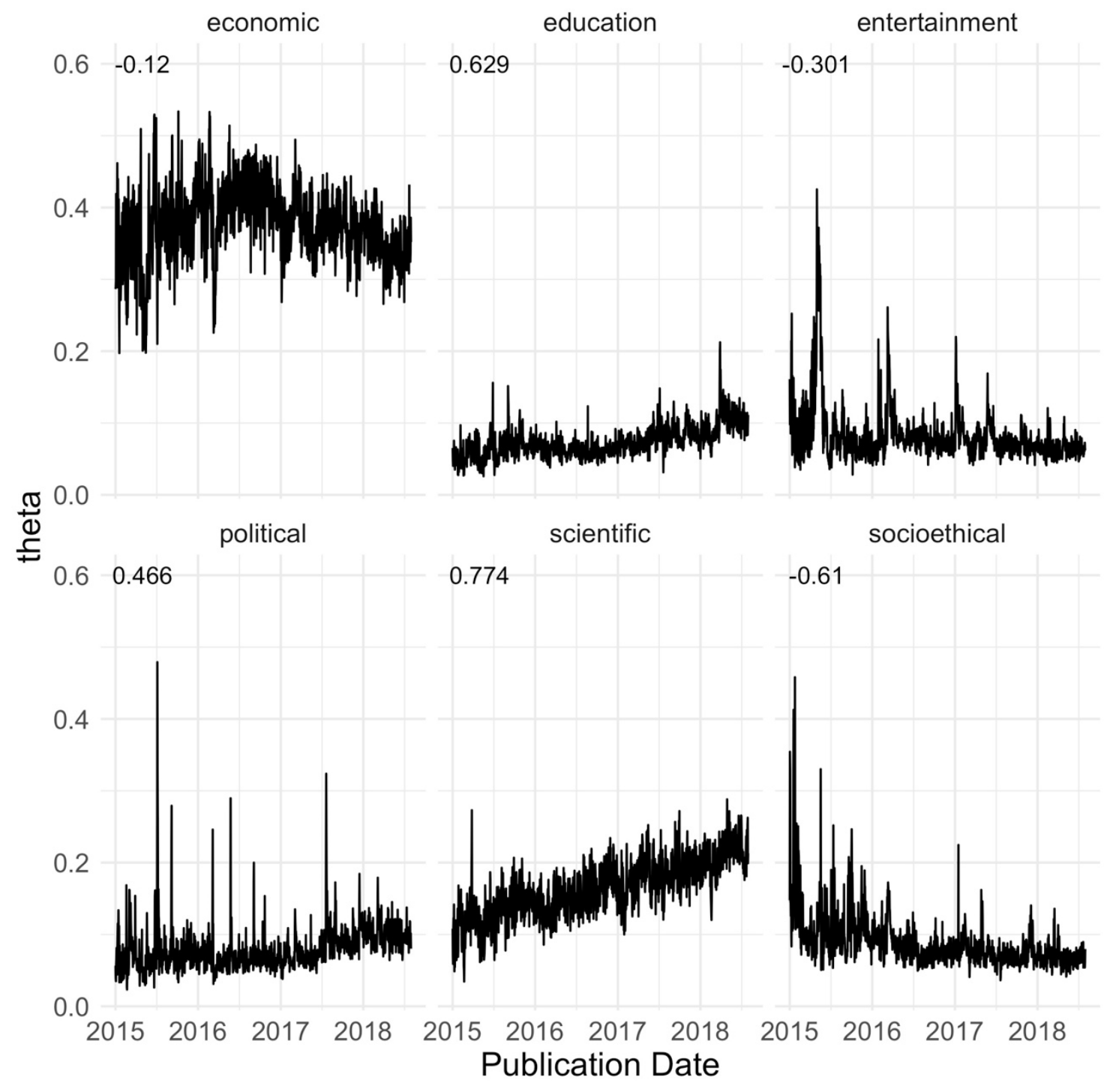

Figure 3. Time series of daily mean theta for each frame of AI articles from WeChat (Note: The numbers on the upper-left corner are Spearman's rank correlation coefficients between theta and time). 


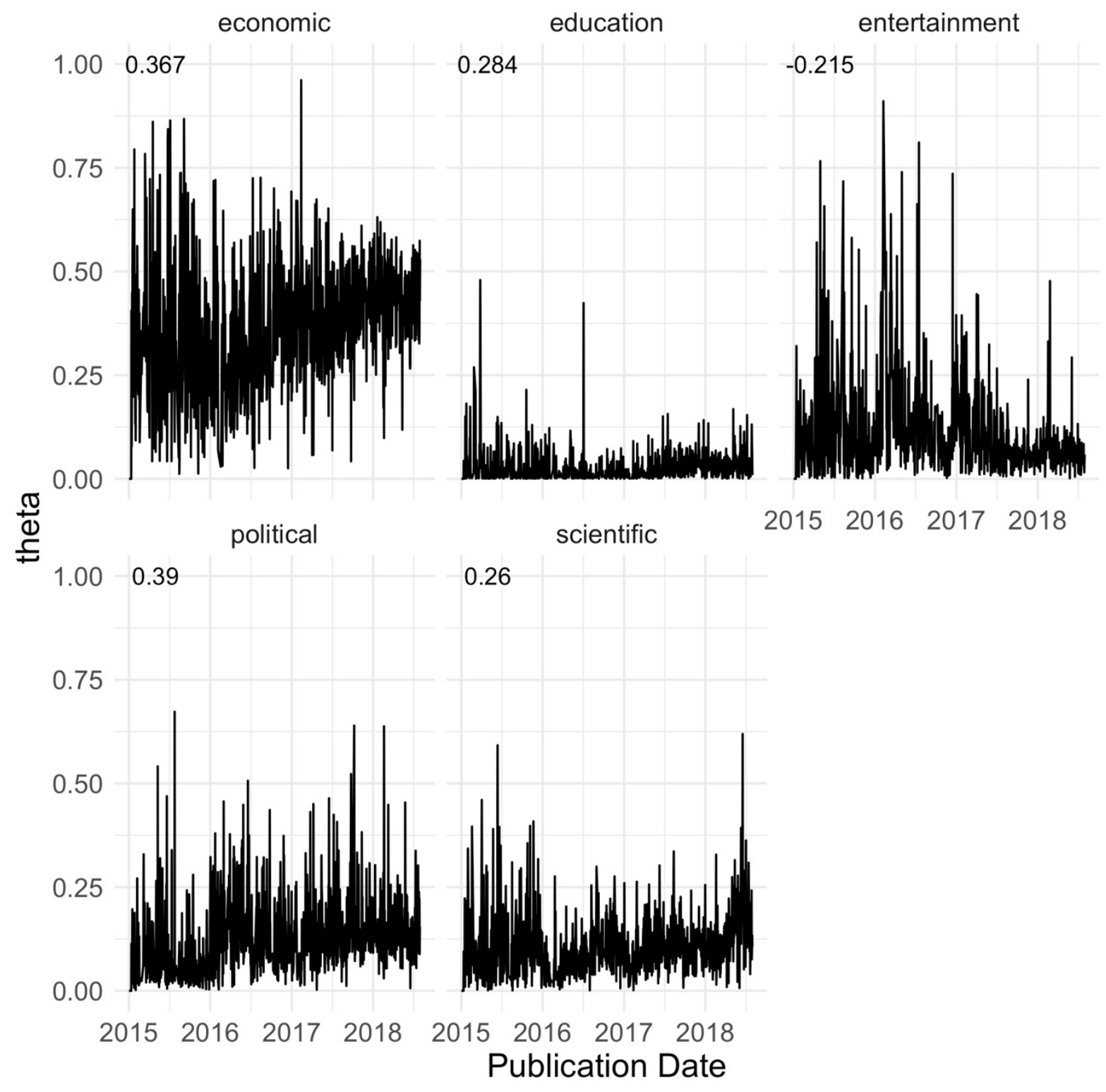

Figure 4. Time series of daily mean theta for each frame of AI articles from $P D$ (Note: The numbers on the upper-left corner are Spearman's rank correlation coefficients between theta and time). 


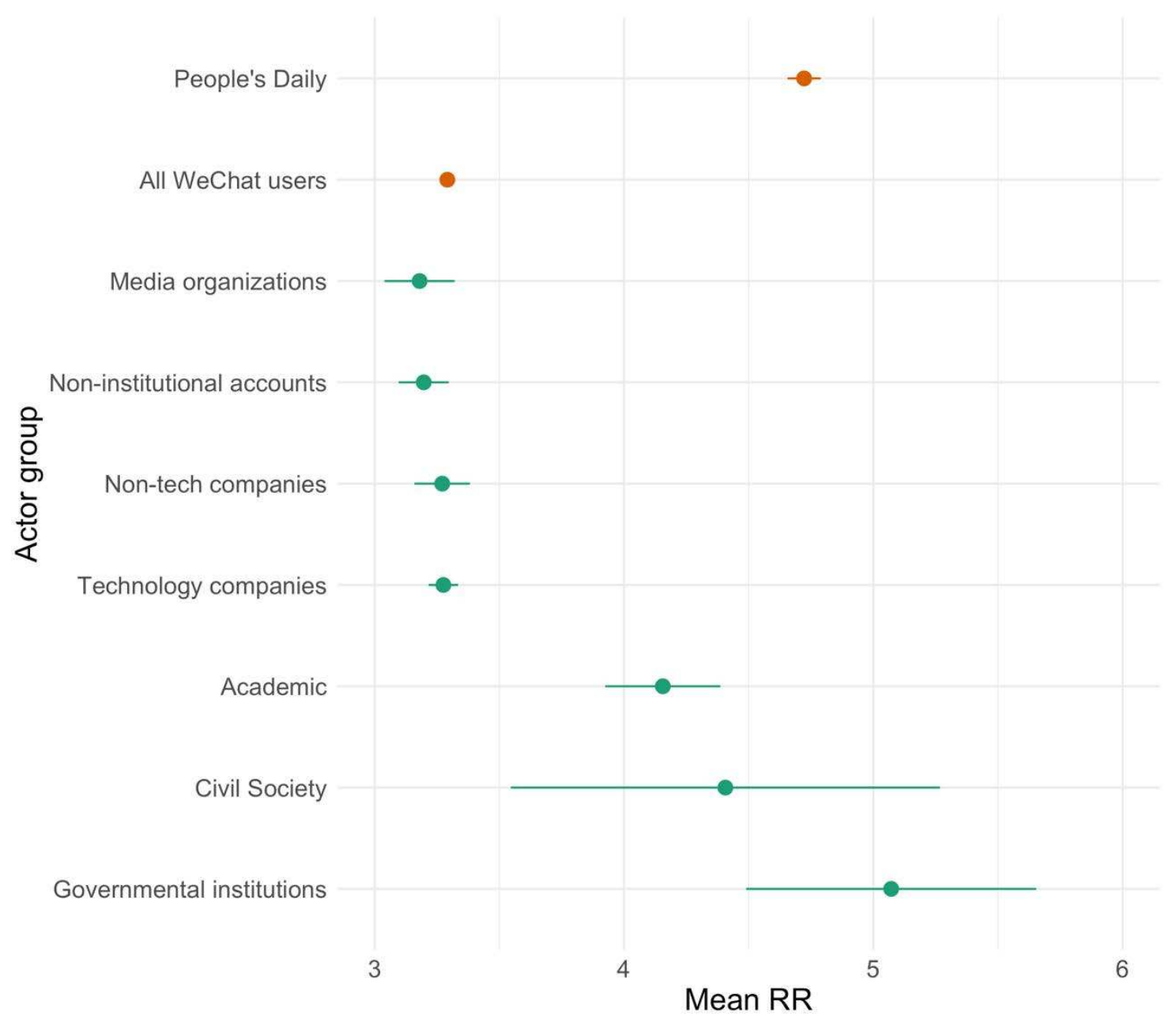

Figure 5. Mean sentiment score (RR) of AI articles from actor groups (Note: The bands around the mean values are $95 \%$ confidence intervals). 


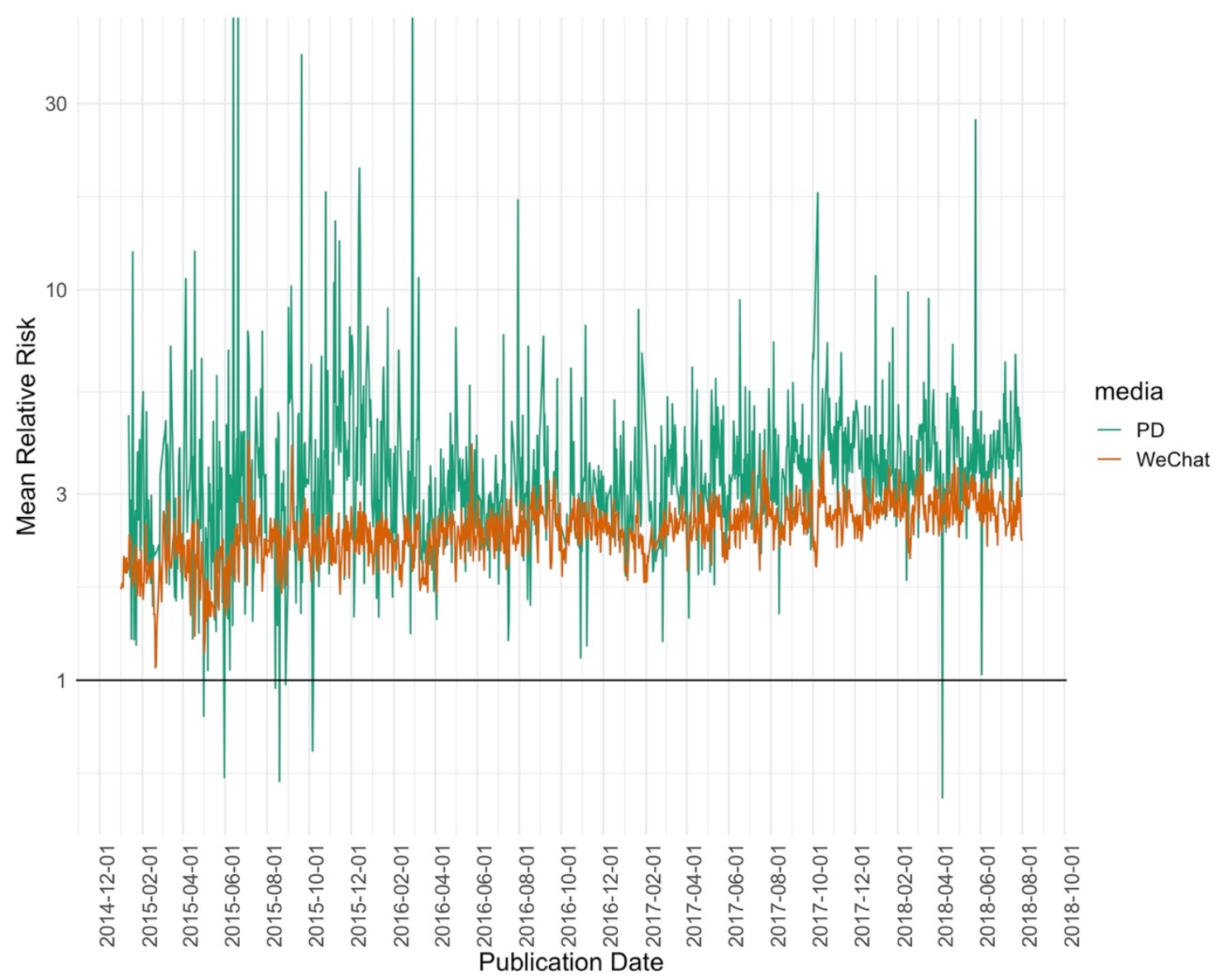

Figure 6. Daily mean RR of AI articles on PD and WeChat. 
Editor Preview of Task - $x+$

未来的第三代仿真机器人已经可以看家、做饭、管理行程, 甚至成为性伴侣。这一天, 质检员发 现刚刚下线的女机器人有质量问题...... 《卡拉 (Kara) 》精彩科幻视频, 非常值得一看 : 播放马 云称，现在正处于变革时期，人类已经从IT走向了DT（数据科技时代），DT时代企业的主角是机 器人。“IT时代是把人当机器, 未来DT时代是把机器当人, 中间的挑战远远超过我们的想象。”马 云畅想, “在数据时代, 30 年以后世界上最优秀的CEO可能是一个机器人。”谷歌旗下机器人 Cheetah速度全球第一, 可达每小时47公里 厨房机器人现较为普遍 医疗领域, 达芬奇机器人正在 给葡萄缝制表皮无人机方向, 大疆亦出了最新概念机还有少不了Dobot的机械臂, 其最大的杀手 锏莫过于用语音或肢体语言来控制它, 甚至用意念来控制! 可是面对机器人, 也有不一样的声 音，斯蒂芬·霍金教授说：“未来100年内，电脑将凭借人工智能把人类取而代之。人工智能的全面 发展或许意味着人类的终结。人工智能将会自我觉醒, 以不断增加的速度重新设计自我。而人类 受到缓慢的生物进化的制约, 将无力竞争, 最终被取代。”那么你怎么看呢?

What is the sentiment of this article? (required)

\begin{tabular}{|lllllll}
\hline & 1 & 2 & 3 & 4 & \\
Very Negative & 0 & 0 & 0 & 0 & Very Positive \\
\hline
\end{tabular}

Figure 7. Screenshot of an example task. 


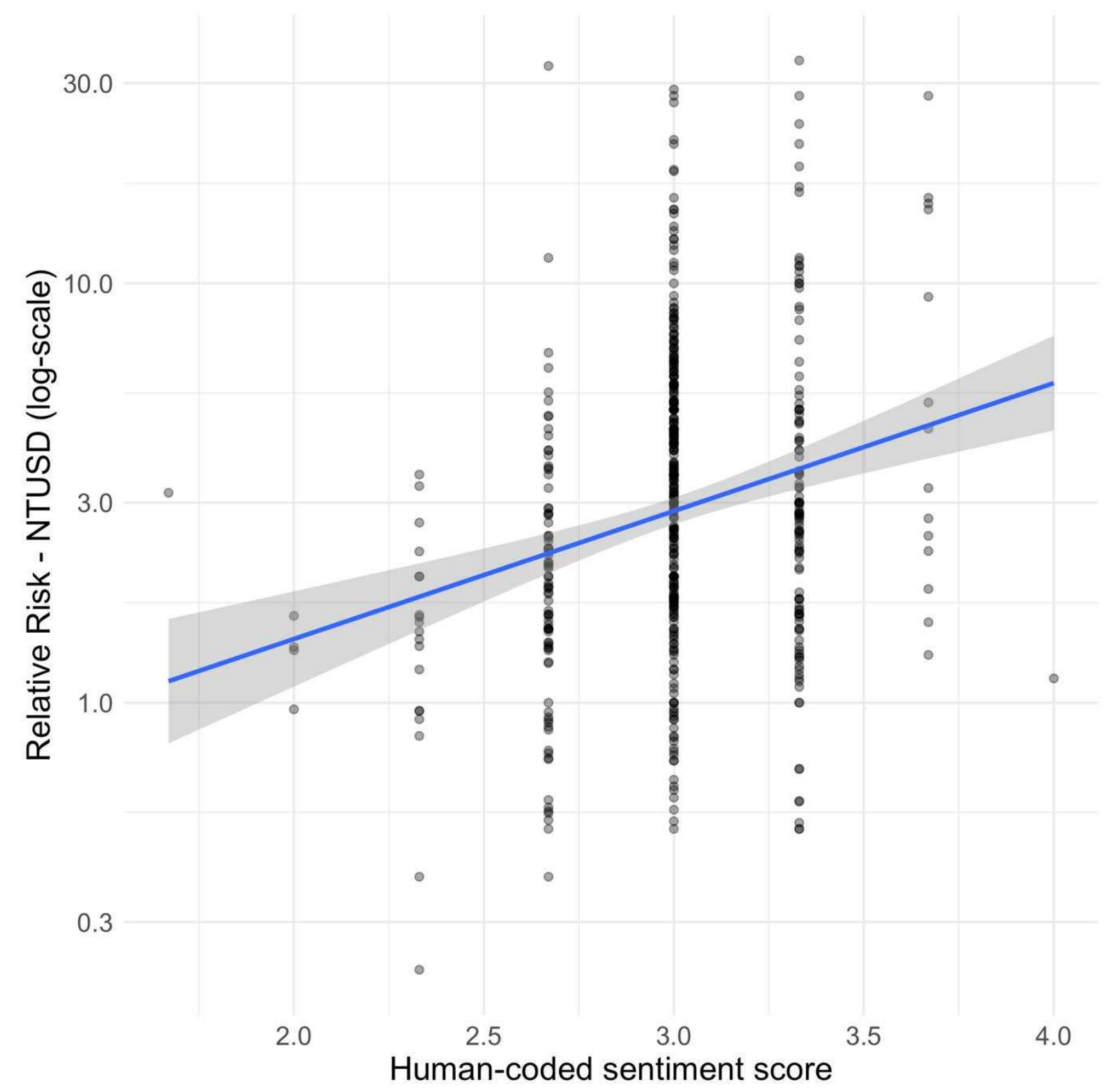

Figure 8. Hand-coded sentiment vs NTUSD 